\title{
A Case Report of Pseudoxanthoma Elasticum-like Papillary Dermal Elastolysis
}

\author{
Jehad O. Hariri, MBBS, FRCPC \\ Dermatology Department, Faculty of Medicine \\ King Abdulaziz University, Jeddah, Saudi Arabia
}

\section{Correspondence}

Dr. Jehad O. Hariri

P.O Box 80216, Jeddah 21589

Saudi Arabia

e.M: jharieri@kau.edu.sa

\section{Submission: 20 Dec. 2015}

Accepted: $\quad 28$ Feb. 2016

\section{Citation}

Hariri JO. A case report of pseudoxanthoma elasticum-like papillary dermal elastolysis. JKAU Med Sci 2016; 23 (2): 49-53. DOI: 10.4197/Med. 23.2.6

\begin{abstract}
Pseudoxanthoma elasticum-like papillary dermal elastolysis is a relatively rare disorder within the literature. Increased awareness of this entity will broaden the differential diagnoses among dermatologists encountering such a condition. Pseudoxanthoma elasticum-like papillary dermal elastolysis tends to occur predominantly in elderly females. Clinically, the lesions present as papules and cobblestone plaques on the neck, resembling pseudoxanthoma elasticum. Histologically, there is absence of elastic fibers in the papillary dermis, and no calcification of the remaining fibers. Pseudoxanthoma elasticum-like papillary dermal elastolysis differs from Pseudoxanthoma elasticum by the absence of systemic manifestations, hence patients are reassured and no further workup is warranted. As of now, no effective treatments are available for this entity. Pseudoxanthoma elasticum-like papillary dermal elastolysis should be in the differential diagnosis of a dermatologist when encountering a clinical presentation of Pseudoxanthoma elasticum in an elderly patient localized to the neck, with absence of fragmented and calcified elastic fibers on histologic examination.
\end{abstract}

\section{Keywords}

Elastic fibers; Cobblestone; Neck

\section{Introduction}

$P$ seudoxanthoma elasticum-like papillary dermal elastolysis (PXE-PDE) is a rare disorder of elastic tissue characterized by clinical lesions resembling pseudoxanthoma elasticum (PXE ${ }^{[1,2]}$. It is an acquired condition, and tends to affect elderly women between the ages of 60 and $80^{[2]}$. These lesions are small non-follicular papules that tend to coalesce, forming cobblestone-like plaques. Their distribution is symmetrical around the neck and in the area over the clavicle, and to a lesser degree in the axilla and antecubital fossa, and on the abdomen. Unlike PXE,
PXE-PDE has no associated systemic manifestations and no increased mortality ${ }^{[3]}$.

The pathogenesis of PXE-PDE is unknown. Usually, no history of excessive prior sun exposure, urticarial reaction or inflammatory dermatosis is elicited ${ }^{[4-6]}$. Although abnormal elastogenesis has been suggested as being of importance, it has been proposed that this condition represents an intrinsic aging phenomenon ${ }^{[1]}$.

Histologically, there is a complete loss of elastic fibers in the papillary dermis. The remaining fibers are not calcified or fragmented; that is, there are no histopathologic features of PXE. Elastophagocytosis 
was present in one case, suggesting that this may be the mechanism for the loss of elastic fibers ${ }^{[7]}$.

\section{Case History}

A 71 year-old woman, presented with a 1-2 year history of asymptomatic yellow colored papules coalescing into plaques on both sides of the neck (Fig. 1). No other body sites were involved. There was no family history of any similar condition in other family members. The patient was otherwise healthy, with no other systemic complaints. Given the clinical resemblance to PXE, an ophthalmology consult was performed to rule out the presence of angioid streaks. The eye examination was normal.

\section{Histological Findings}

A skin punch biopsy was performed, and the Hematoxylin and Eosin sections showed a normal appearing epidermis and dermis (Fig. 2). An elastin stain was performed and revealed absence of elastic fibers in the papillary dermis (Fig. 3).

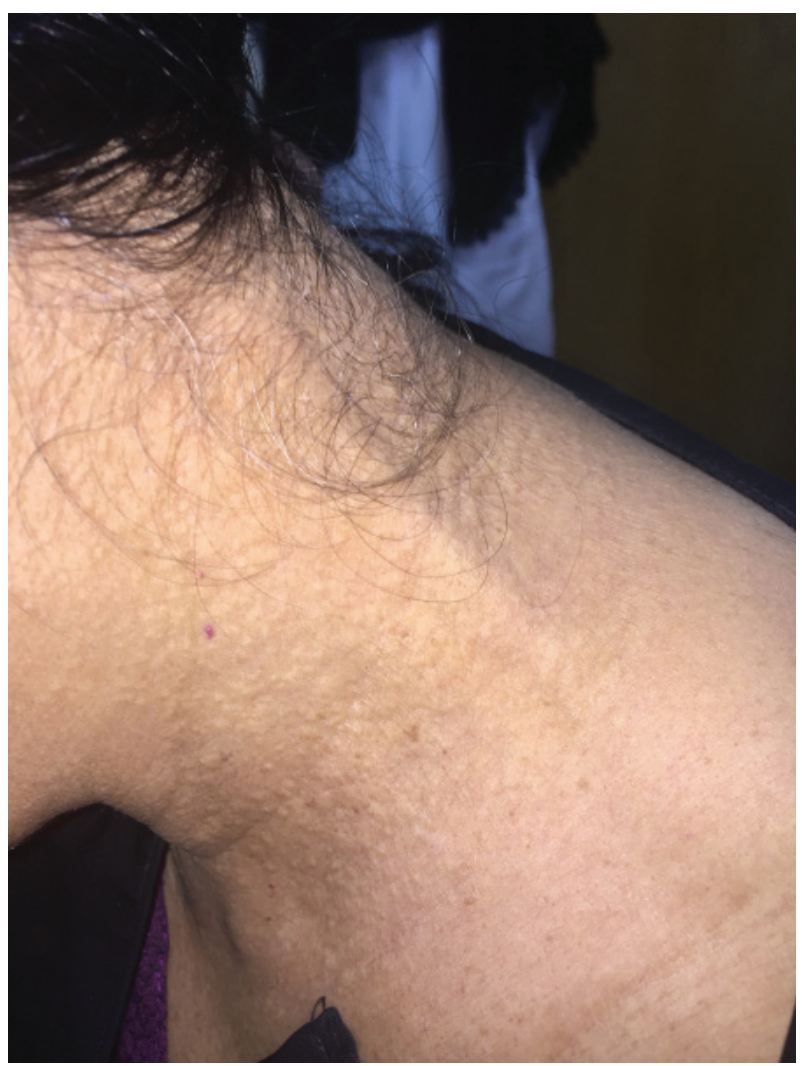

Figure 1. Skin with yellow colored papules on the lateral side of the neck.

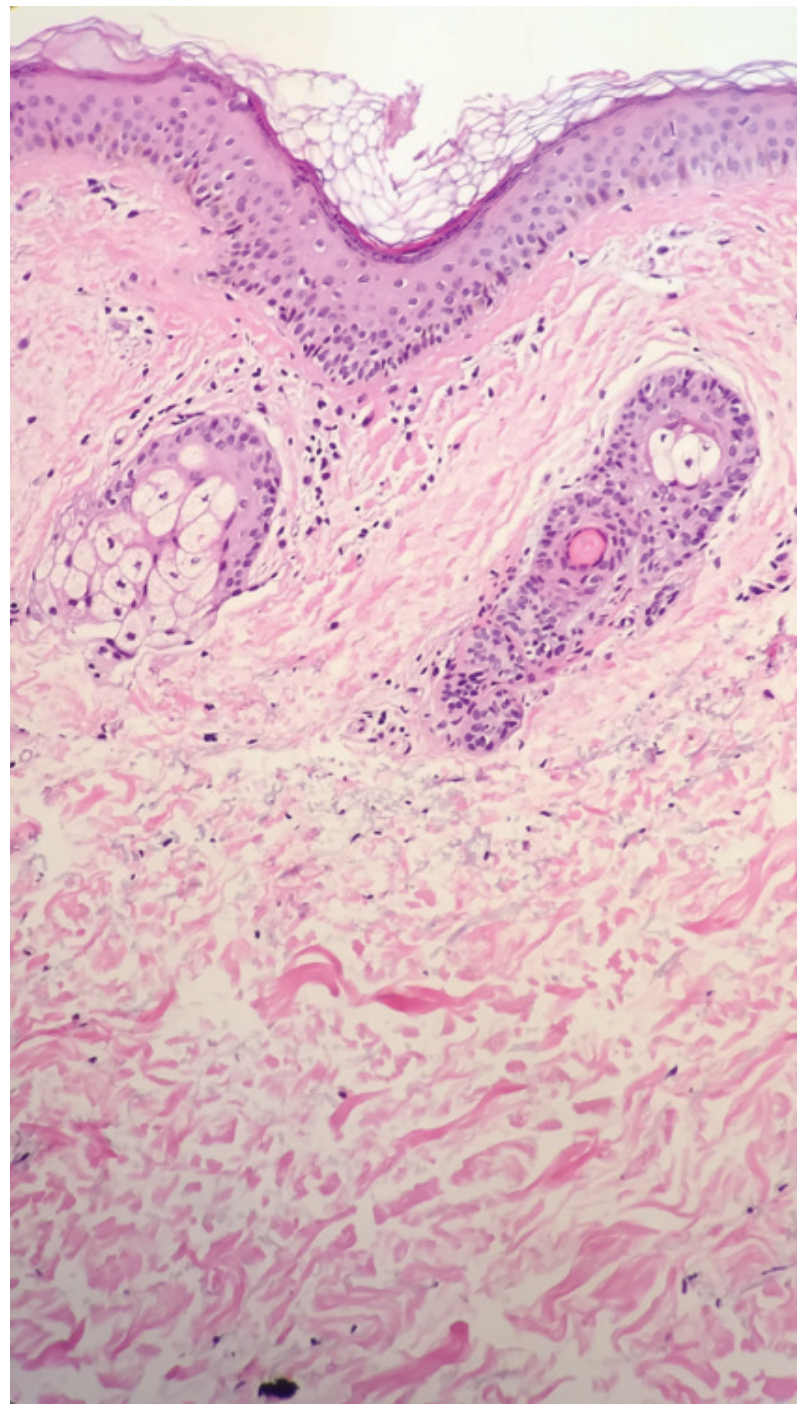

Figure 2. Biopsy specimen of the relatively normal appearing epidermis and dermis (Hematoxylin and Eosin, X20).

\section{Follow-up and Management}

The patient was seen on follow up, and felt reassured that no systemic manifestations were associated with this disorder. The lesions were stable and asymptomatic. We did not pursue any treatment modalities, as the current literature shows no effective treatment as of now.

\section{Discussion}

When faced with an elderly patient presenting with yellowish colored papules on the neck and other flexural areas, the first clinical impression among most dermatologists is PXE. However, PXE is hereditary, tends to present within the first and second decades of life, 


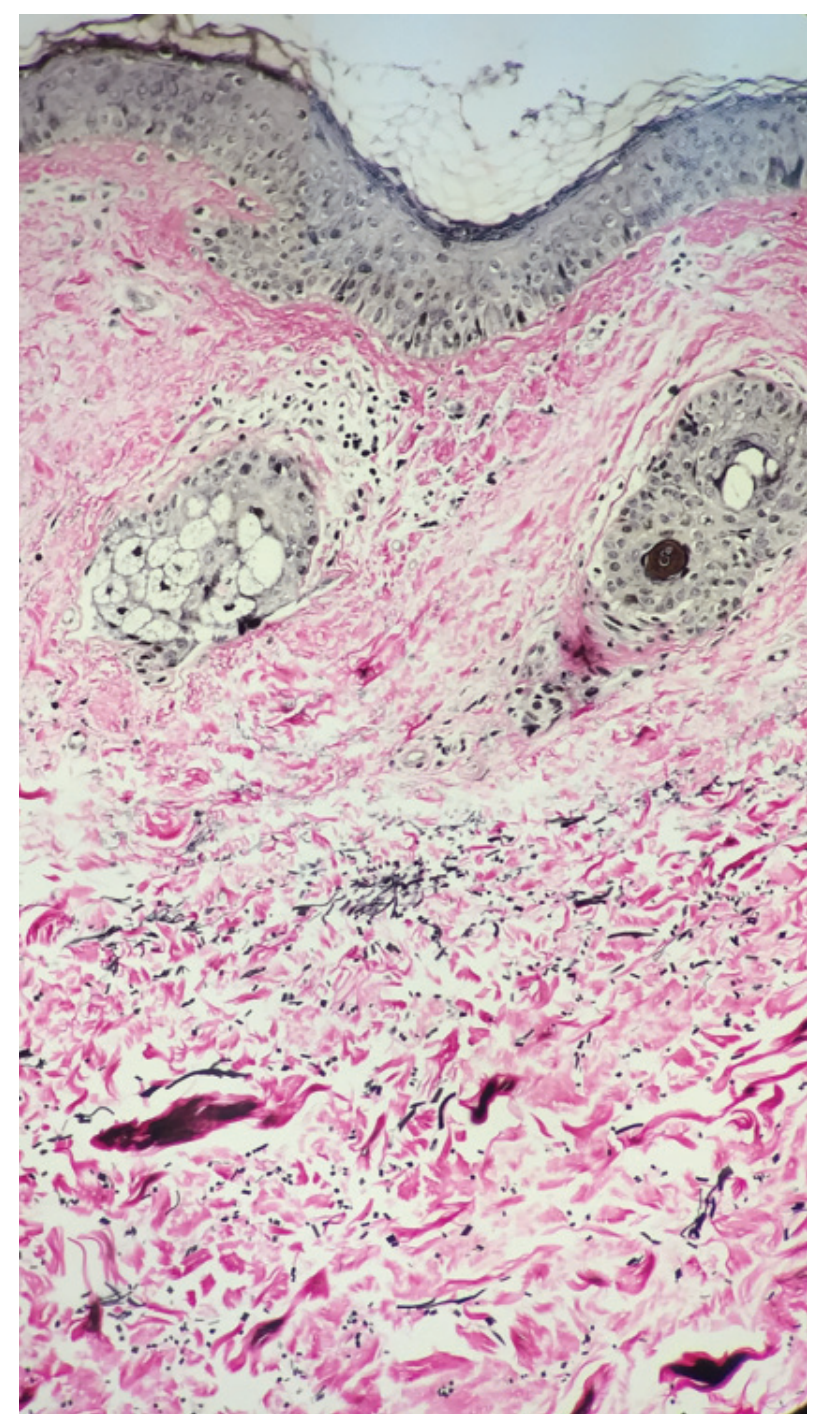

Figure 3. An elastin stain showing decreased elastic fibers in the papillary dermis (X20).

and virtually all patients have ophthalmologic findings of Angioid streaks at the time of presentation ${ }^{[8-12]}$. Histologically, there are fragmented and calcified elastic fibers in the mid-dermis ${ }^{[13]}$. Another important differential diagnosis to keep in mind is focal dermal elastosis (FDE). This entity tends to present with the same age, distribution, and clinical presentation of PXEPDE. However, on histological examination, there is an increase in the amount of elastic fibers in the mid and deep dermis. The elastic fibers are neither fragmented/ calcified in the mid-dermis (as in PXE) or absent in the papillary dermis (as in PXE-PDE). This entity has no systemic involvement as well ${ }^{[14]}$.

\section{Conclusion}

Whether PXE-PDE is truly a rare condition, or simply under-reported is yet to be confirmed. That being said, when facing a patient presenting with yellow colored papules on the neck, the following should be considered. If the patient is young, and the skin punch biopsy results show calcified and fragmented elastic fibers in the mid-dermis, a diagnosis of PXE is highly likely and an ophthalmology consultation is warranted. If on the other hand the patient is elderly, then the differential diagnosis includes either FDE or PXE-PDE. If the biopsy results show an increased amount of elastic fibers in the mid and deep dermis, a diagnosis of FDE is favored. However, if elastic fibers were absent in a band-like pattern in the papillary dermis, this would support the diagnosis of PXE-PDE. Patients should be reassured and no further systemic workup is needed.

\section{Conflict of Interest}

The author has no conflict of interest.

\section{Disclosure}

The author did not receive any type of commercial support either in forms of compensation or financial for this study. The author has no financial interest in any of the products or devices, or drugs mentioned in this article.

\section{Ethical Approval}

Ethical approval was obtained with reference number 432-16 from the Unit Biomedical Ethics Research Committee, Faculty of Medicine, King Abdulaziz University.

\section{References}

[1] Rongioletti F, Rebora A. Fibroelastolytic patterns of intrinsic skin aging: pseudoxanthoma elasticum-like papillary dermal elastolysis and white fibrous papulosis of the neck. Dermatology 1995; 191(1): 19-24.

[2] el-Charif MA, Mousawi AM, Rubeiz NG, Kibbi AG. Pseudoxanthoma elasticum-like papillary dermal elastolysis: a report of two cases. J Cutan Pathol 1994; 21(3): 252-255.

[3] Rongioletti F, Izakovic J, Romanelli P, Lanuti E, Miteva M. Pseudoxanthoma elasticum-like papillary dermal elastolysis: A large case series with clinicopathological correlation. J Am Acad Dermatol 2012; 67(1): 128-135. 
[4] Vargas-Díez E, Peñas PF, Fraga J, Aragües M, García-Díez A. Pseudoxanthoma elasticum-like papillary dermal elastolysis. A report of two cases and review of the literature. Acta Derm Venereol 1997; 77(1): 43-45.

[5] Ohnishi Y, Tajima S, Ishibashi A, Inazumi T, Sasaki T, Sakamoto H. Pseudoxanthoma elasticum-like papillary dermal elastolysis: report of four Japanese cases and an immunohistochemical study of elastin and fibrillin-1. Br J Dermatol 1998; 139(1): 141-144.

[6] Lee HS, Song HJ, Hong WK, Shin JH, Choi GS. Pseudoxanthoma elasticum-like papillary dermal elastolysis with solar elastosis. J Eur Acad Dermatol Venereol 2008; 22(3): 368-369.

[7] Hashimoto K, Tye MJ. Upper dermal elastolysis: a comparative study with mid-dermal elastolysis. J Cutan Pathol 1994; 21(6): 533-554.

[8] Neldner KH. Pseudoxanthoma elasticum. Int J Dermatol 1988; 27(2): 98-100.

[9] Woo TY, Rasmussen JE. Disorders of transepidermal elimination: Part 2. Int J Dermatol 1985; 24(6): 337-348.

[10] GOODMAN RM, SMITH EW, PATON D, BERGMAN RA, SIEGEL CL, OTTESEN OE, SHELLEY WM, PUSCH AL, MCKUSICK VA. Pseudoxanthoma elasticum: A clinical and histopathological study. Medicine (Baltimore) 1963; 42: 297-334.

[11] Larralde M, Markan PA, Peruffo L, Calb I, Magariños G. Yellowish papules on flexural areas of a child. Pediatr Dermatol 2002; 19(6): 557-559.

[12] Egawa Y, Tanioka M, Araki E, Taki R, Miyachi Y, Utani A. Redbrown macules on the abdomen. Clin Exp Dermatol 2008; 33(2): 219-220.

[13] Hosen MJ, Lamoen A, De Paepe A, Vanakker OM. Histopathology of pseudoxanthoma elasticum and related disorders: Histological hallmaks and diagnostic clues. Scientifica (Cairo). 2012; 2012: 598262.

[14] Tajima S, Shimizu K, Izumi T, Kurihara S, Harada T. Late-onset focal dermal elastosis: clinical and histological features. Br J Dermatol 1995; 133(2): 303-305. 


\title{
تقرير حالة ورم أصفر كاذب مرن مثل اتحلال الجلد النسيجي المرن
}

\author{
جهاد اسامة حريزي

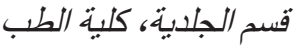 \\ جامعة الملك عبدالعزيز العيز \\ جذة ـ المعلكة العربية السعودية
}

المستخلص. و ورم أصفر كاذب مرن مثل انحلال الجلد النسيجي المرن هو اضطر اب نادر مع عدد قليل من الحالات المبلغ

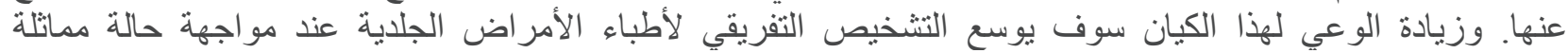
لها. ورم أصفر كاذب مرن مثل انحلال الجلد النسيجي المرن يميل إلى أن يحدث فئ في الغالب في النساء المسنات. سراء سريريا،

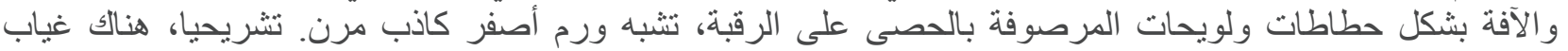

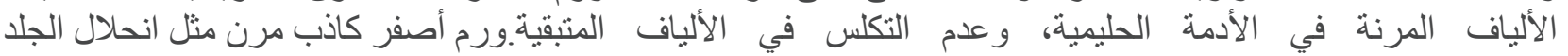

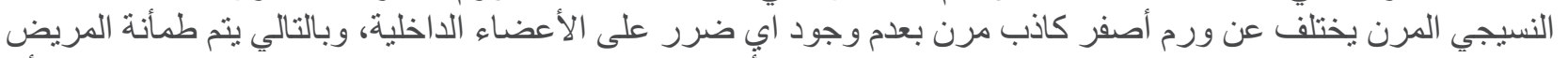

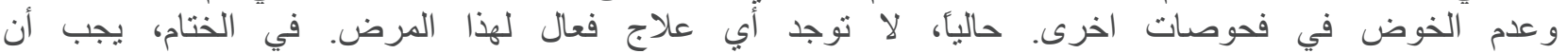

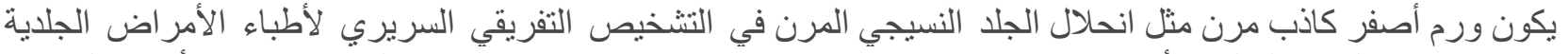

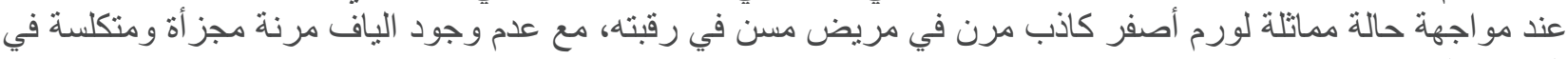
الفحص النسيجي 